\title{
Agnosticism and the balance of evidence
}

DOI:

10.1515/9783110566512-002

Link to publication record in Manchester Research Explorer

\section{Citation for published version (APA):}

Daly, C. (2018). Agnosticism and the balance of evidence. In M. Szatkowski (Ed.), Ontology of theistic beliefs (pp. 1-17). (Philosophische Analyse/ Philosophical Analysis; Vol. 74). de Gruyter, Walter GmbH \& Co. https://doi.org/10.1515/9783110566512-002

\section{Published in:}

Ontology of theistic beliefs

\section{Citing this paper}

Please note that where the full-text provided on Manchester Research Explorer is the Author Accepted Manuscript or Proof version this may differ from the final Published version. If citing, it is advised that you check and use the publisher's definitive version.

\section{General rights}

Copyright and moral rights for the publications made accessible in the Research Explorer are retained by the authors and/or other copyright owners and it is a condition of accessing publications that users recognise and abide by the legal requirements associated with these rights.

\section{Takedown policy}

If you believe that this document breaches copyright please refer to the University of Manchester's Takedown Procedures [http://man.ac.uk/04Y6Bo] or contact uml.scholarlycommunications@manchester.ac.uk providing relevant details, so we can investigate your claim.

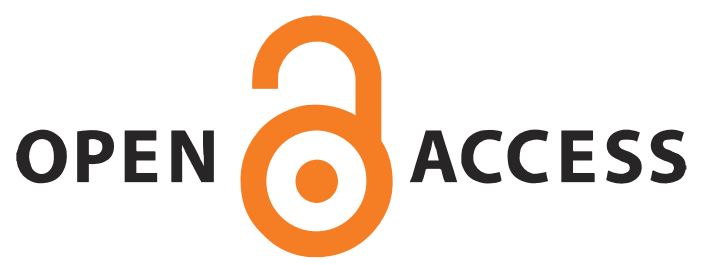




\title{
Chris Daly \\ Agnosticism and the Balance of Evidence
}

\section{Introduction}

The agnostic suspends judgement as to whether there is a God: she neither believes that there is a God nor believes that there is no God. ${ }^{1}$ She and the atheist agree about something: they agree that there is no good evidence that there is God. Some atheists think there is good evidence that there is no God - they cite the problem of evil or argue that the concept of God is incoherent. The agnostic disagrees: she thinks that there is no good evidence that there is no God. Some atheists think that if there is no good evidence that there is a God, that fact itself provides good evidence that there is no God. This contention was memorably expressed in Russell's tale of the cosmic teapot:

\begin{abstract}
Many orthodox people speak as though it were the business of sceptics to disprove received dogmas rather than of dogmatists to prove them. This is, of course, a mistake. If I were to suggest that between the Earth and Mars there is a china teapot revolving about the sun in an elliptical orbit, nobody would be able to disprove my assertion provided I were careful to add that the teapot is too small to be revealed even by our most powerful telescopes. But if I were to go on to say that, since my assertion cannot be disproved, it is intolerable presumption on the part of human reason to doubt it, I should rightly be thought to be talking nonsense. (Russell (1952), pp. 547-548)
\end{abstract}

Russell's teapot hypothesis at once illustrates a principle and provides an analogy. The principle is that, at least in certain circumstances, the lack of evidence for a hypothesis $H$ provides evidence against $H$. The analogy is that, just as the hypothesis that there is a cosmic teapot is not supported by any evidence and therefore there is evidence that it is false, so too the hypothesis that there is a God is not supported by evidence and therefore there is evidence that it is false.

The challenge to the agnostic is evident. She concedes that there is no all things considered evidence that there is a God yet she does not believe that there is no God. Is she thereby irrational? What relevant difference is there between the cosmic teapot hypothesis and the God hypothesis? In this paper I will explore the agnostic's position.

1 By 'God' is meant here an uncreated free agent who created and sustains the universe and who is omnipotent, omniscient and omnibenevolent. 


\section{Agnosticism}

Agnosticism has two components. It consists of a lack of belief and a reason for that lack of belief. An agnostic with respect to the proposition that $p$ neither believes that $p$ nor believes that not- $p$. Her reason for her lack is belief is that there is (or so she believes) insufficient evidence on which to believe that $p$ or to believe that not- $p$. We can deepen our understanding of what agnosticism is by asking a series of questions and answering them by means of introducing a number of distinctions.

What is the agnostic an agnostic about? Here we can distinguish between local and global forms of agnosticism (following Le Poidevin (2010), pp. 10-13). Someone might be agnostic with respect to the propositions drawn from a particular subject-matter. An agnostic about the existence of God is someone who is agnostic with respect to all propositions which imply that God exists. An agnostic about the future is agnostic with respect to all propositions about the future. An agnostic about morality is agnostic with respect to all propositions about what is morally right or wrong. And so on. Each of these is a species of local agnosticism. One might be agnostic with respect to some subject-matters but not others. By contrast, a global agnostic would be someone who is agnostic with respect to all subject-matters and hence to all propositions.

What is the status of the evidence? The agnostic was characterised above as believing that there is insufficient evidence on which to believe that $p$ or on which to believe that not- $p$. 'Evidence' is used in an unrestricted sense: evidence that $p$ is any consideration that provides epistemic reason to believe that $p$. So understood a piece of evidence may be something physical, such as a fingerprint, something mental, such as a perception, or something propositional, such as an argument. In claiming that there is no evidence for or against $p$, the agnostic is making a fallible claim. She might have overlooked certain evidence or she might have mistakenly judged that something is not relevant evidence. So denying that there is evidence for or against $p$ may be as controversial as claiming that there is such evidence.

There are a number of options which an agnostic might take with respect to the issue of the evidence before her. One option is that she may believe that there is some evidence for $p$, or for not- $p$, or for both, but she will further believe that what evidence there is fails to raise her degree of belief so that she thinks that it is more likely than not that $p$ (or so that she thinks that it is more likely than not that not- $p$ ) (cf. Draper (2001)). In such a case, either she thinks that the evidence 
each way is balanced or she is unable to say where the balance of evidence lies. ${ }^{2} \mathrm{~A}$ second option is that she may believe that there is simply no evidence for $p$ or for not- $p$. The two preceding options allow that the evidential situation in which the agnostic finds herself may change. Each option allows that evidence might come in which would make her believe that $p$ or which would make her believe that not$p$. This would be to take it that it is contingent that she lacks sufficient evidence either way. A third option, however, would be for her to believe that there cannot be evidence either way. This option would be to take it that it is necessary that she lacks sufficient evidence either way. I take this to be the view Kant took in his Critique of Pure Reason with respect to the existence of God. ${ }^{3}$ Call it Kantian agnosticism. (Kant held a further view: that practical reason enjoins us to think and act as if God exists. This further view of his will not concern us).

A fourth option is that, although there is a wealth of evidence for and against $p$, the evidence is too disputed. For instance, many people have had religious experiences in which they are apparently aware of God. The content of such experiences, however, is compatible with many different hypotheses about the source of those experiences, some theistic, some not. We then need to distinguish agreed evidence from disputed evidence. On the one hand, what is agreed evidence between all parties to the dispute is that many people have had experiences with the above content. That evidence, however, seems not to support a theistic hypothesis more than it supports some non-theistic hypothesis. On the other hand, whether there is evidence that many people have experiences which are in fact experiences of God is disputed. The distinction between agreed and disputed evidence does not coincide with the distinction between evidence that is open to all and evidence that is open only to some. ${ }^{4}$ It should be granted that the identification and proper weighing of evidence that is relevant to a given debate very often requires specialised training and competence. Identifying something as an $\mathrm{X}$-ray image and being able to interpret it correctly is a relatively specialised task and not something open to all. Nevertheless, the information it provides is evidence that closely bears on the question of whether you have a broken leg. In the present case, the relevant training and competence is primarily training and competence in philosophy. By 'parties to the dispute', then, we mean suitably spe-

2 For simplicity by 'having evidence', I assume both that one has evidence and that one has evaluated this evidence. These would come apart, for instance, in a situation in which I have $\mathrm{x}$-rays of a body but I am not sufficiently trained to be able to interpret them.

3 See the Transcendental Dialectic's Ideal of Reason in Kant (1781).

4 Shalkowski (1989), p. 4, invokes the latter distinction in his discussion of evidence for or against the existence of God. 
cialised and informed parties. Professional philosophers who meet the standards of proficiency for the discipline - as indicated by such factors as that they have secured tenure, are employed as journal referees, and so on - persistently disagree about whether the content of people's religious experiences is evidence that there is a God. For that reason the content of people's religious experiences is disputed evidence that there is a God.

One further matter on the topic of evidence should be noted. Some theists claim that their belief that there is a God is a rational belief because, they claim, God created human beings in such a way that, in suitable circumstances, human beings will acquire (inter alia) a rational belief that there is a God (Plantinga (1983)). It follows from this view that someone's belief that there is a God can be rational although not based on evidence. The agnostic need not claim that such a view is false. Instead, she suspends judgement about it. Part of her reason is consistency: if she suspends judgement about whether there is a God, a fortiori she suspends judgement about the fashion in which God has created and fashioned us. Another part of her reason is evidential: just as she thinks that there is no evidence that there is a God, so too she thinks that there is no evidence that the above view is true.

What is the epistemic standing of agnosticism? The agnostic may believe that her lack of evidence makes it epistemically permissible neither to believe that $p$ nor to believe that not- $p$. On this option, given what evidence (if any) she has, it is reasonable for her neither to believe that $p$ nor to believe that not- $p$, but this is not to say that it would be unreasonable for someone to believe that $p$ or for someone to believe that not- $p$, given the same evidence. Alternatively, the agnostic may believe that her lack of evidence makes it epistemically obligatory for her neither to believe that $p$ nor to believe that not- $p$. On this option, given what evidence she has, it is reasonable for her neither to believe that $p$ nor to believe that not- $p$, and it would be unreasonable for someone to believe that $p$ or for someone to believe that not- $p$, given the same evidence (cf. Oppy (1994)).

If the agnostic thought both that there was no evidence that $p$ and that there was no evidence that not- $p$, or if she thought that there cannot be evidence of either sort, then she would take this second option: she would think that it is epistemically obligatory for her neither to believe that $p$ nor to believe that not- $p$. If, however, she thought that there was some evidence that $p$, say, then on some views of reasonable belief (such as Rosen (2001)) there can be cases in which two people have the same body of evidence such that this evidence makes it reasonable for one person to believe that $p$ although not for another. Such views are controversial (Feldman (2007)); I simply note them here for the record.

Who is the agnostic speaking for? The agnostic may be speaking for herself or she may be speaking for a larger epistemic community. In the first case, she 
may be reporting that she is agnostic given the evidence available to her while allowing that other people may have different evidence. If she does not know what evidence they have, she cannot speak for them and say what attitudes it would be reasonable for them to take with respect to $p$ or with respect to not- $p$. For instance, suppose the agnostic thinks that it is a contingent fact that there is not enough evidence for her to believe that $p$ or to believe that not- $p$. Still, she might allow that other inquirers are in a better epistemic situation than she is. Alternatively, the agnostic might take herself to be speaking for a larger epistemic community. She might take it that she is not simply talking on the basis of the evidence which is available to her but on the basis of the evidence available to her epistemic community. This epistemic community might be her research team, her intellectual culture, or even the human race as a whole. If, for instance, an agnostic thought that there could be no evidence for or against a given proposition $p$, then she would presumably be speaking not just about her own epistemic situation but that of every human being. For suppose that someone other than the agnostic had evidence that $p$. Then that person's testimony that $p$ could provide the agnostic with some evidence that $p$.

\section{Russell's teapot hypothesis}

Russell's own intention in presenting the teapot hypothesis may have differed from what a proponent of the above principle and analogy takes it to show. Russell's intention may have only been to argue that in a debate about whether some existential hypothesis $H$ is true, the onus of proof is not automatically on someone who doubts whether $H$. He may also have intended to argue that in such a debate the onus of proof is on someone who claims that $H$. At any rate, some philosophers have independently found such claims convincing. Consider the following passage:

for any proposition, $p$, there is an onus of proof on the person who claims that it is known that $p$ is true (or false) which does not rest on the person who denies this. Thus, the person who claims that it is known that there is life on Mars is epistemically obliged to adduce evidence for his claim, even if there is no evidence that there is no life on Mars, while it is surely false that the person who claims that it is not known that there is life on Mars is equally epistemically obliged to adduce evidence for his position, if there is no evidence that there is life there. (Dore (1982), p. 505)

The issue concerning where (if anywhere) the onus of proof lies in a given debate is, however, more complex than this. The issue is also sensitive to the subject- 
matter under question. For example, Dore knows what his name is. If someone - a tax officer or some other bureaucrat - were to deny that his name is 'Dore', the onus of proof is not on Dore to adduce evidence that he knows his own name. Indeed, the onus rests on the denier for perversely denying that Dore knows what he takes himself to know. The fact that where the onus of proof lies is sensitive to the subject-matter under debate is veiled in the passage quoted above by its choice of subject-matter. In both every day and philosophical contexts, it is controversial whether there is life on Mars and so it is controversial whether anyone knows whether there is life on Mars or not. By contrast, in an everyday or philosophical context it is uncontroversial that Dore knows his own name. We enter such contexts with (what we take to be) a vast stock of knowledge and reasonable belief, some personal and some mutual. Given this presumed basis of knowledge and reasonable belief, the onus of proof falls on someone either when she seeks to augment it (as when she claims that there is life on Mars) or when she seeks to diminish it (as when she denies that Dore knows his own name). In the latter case, in an everyday context the denier might cite evidence of Dore's apparent amnesia, and in a philosophical context the denier might cite Descartes' dreaming argument as evidence that we know very little of what we take ourselves to know. Be that as it may, the point is that they would need to cite some such considerations to support their denial. ${ }^{5}$

I assume that Russell is claiming more than that the onus of argument is on anyone who asserts that there is a cosmic teapot. I take him also to be claiming that it is reasonable to believe that that hypothesis is false, that we do not need evidence that it is false, and that we should revise our belief only if we were given evidence that it is true (Le Poidevin (2010), p. 42, and Van Inwagen (2012), p. 22). Just how Russell's argument is to be spelt out is not obvious. For definiteness, let us work with the following interpretation. Even if it does not exactly reflect the argument Russell had in mind, the interpretation is of interest in its own right and it might capture what many philosophers had in mind when they endorsed what they took to be Russell's argument. The interpretation takes Russell to be running the following argument that no cosmic teapot exists:

(T1) Consider the hypothesis that between the Earth and Mars there is a china teapot in orbit around the sun: call this hypothesis teapot.

(T2) There is no evidence that teapot is true.

(T3) So the probability of teapot is very close to zero.

(T4) So we should believe that teapot is false.

5 For further discussion of the issue of the context-dependent nature of burdens of proof, see Shalkowski (1989) especially pp. 1-9. 
By analogy, Russell is then arguing in the following way that God does not exist:

(G1) Consider the hypothesis that there is a God: call this hypothesis theism.

(G2) There is no evidence that theism is true.

(G3) So the probability of theism is very close to zero.

(G4) So we should believe that theism is false.

\title{
4 Van Inwagen's response
}

Teapot is one of a number of whimsical hypotheses which have achieved currency in academic and popular discussions of the existence of God. The strategy behind their introduction is to claim that there is no more reason to accept theism than there is to accept any of the whimsical hypotheses, and so theism is taken to be no more probable than any of the whimsical hypotheses. Since each of the whimsical hypotheses itself has very low probability, theism will also have a low probability. Accordingly, we have a list of hypotheses such as the following:

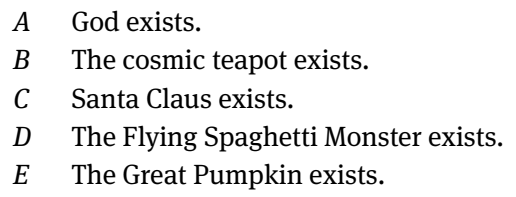

For instance, the following passage forms part of Scriven's presentation of his case for disbelief that God exists:

\begin{abstract}
Why do adults not believe in Santa Claus? Simply because they can now explain the phenomena for which Santa Claus's existence is invoked without any need for invoking a novel entity.... As we grow up, no one comes forward to prove that [Santa Claus] does not exist. We just come to see that there is not the least reason to believe he does exist.... Santa Claus is in the same position as fairy godmothers, wicked witches, the devil, and the ether ... the proper alternative when there is no evidence is not mere suspension of belief [in Santa Claus], it is disbelief. (Scriven (1966), p. 103)
\end{abstract}

Van Inwagen dismisses $C$ - $E$ on the ground that the entities in question or their supposed activities are physically impossible. (This was the reason given in van Inwagen's lecture 'Russell's Teapot' given at Syracuse University on $22^{\text {nd }}$ September 2012 and available online. ${ }^{6}$ His print publication (Van Inwagen (2012)) does

6 See http://andrewmbailey.com/pvi/Teapot.pdf at pp. 8-9. 
not contain this material). Nothing can travel at sufficient speed to visit every home on Christmas morning, and something composed solely of spaghetti or pumpkin cannot fly and cannot be sentient. Fair enough. But Hume offered various theological hypotheses which are rivals to theism, which each have low prior probability, but which cannot be excluded on the grounds that they are physically impossible (Hume (1779), part 5, paragraph 12):

\footnotetext{
F 'some infant Deity, who afterwards abandoned [the world], ashamed of his lame performance';

$G$ '[the world is] the production of old age and dotage in some superannuated Deity'.
}

We will return to these examples below.

Van Inwagen claims that Russell's argument against teapot goes through only if a further premise is added:

$\left(T 2^{\prime}\right)$ Teapot has a vanishingly small prior probability of being true.

$\left(T 2^{\prime}\right)$ says that teapot has a low probability of being true prior to any considerations pertaining to evidence. Why is this? There are countless possible stories about the origin of the teapot and how it came to occupy an orbit between the Earth and Mars. Each of these origin stories, with its tales of aliens manufacturing a teapot and putting it into orbit, has a very low probability. The aggregate probability of all of these origin stories is also very low. The prior probability of teapot is equal to that aggregate probability. So the prior probability of teapot is very low. Since there is no evidence for teapot - as (T2) reports - its probability remains very low; indeed it is close to zero - as (T3) reports (Van Inwagen (2012), pp. 21-22).

Van Inwagen thinks that a premise corresponding to $\left(T 2^{\prime}\right)$ needs to be added to Russell's presumed argument against theism:

$\left(G 2^{\prime}\right)$ Theism has a vanishingly small prior probability of being true.

But while van Inwagen is prepared to accept $\left(T 2^{\prime}\right)$ and thereby let $(T 4)$, the conclusion of the teapot argument, go through, he claims that we are not in a position to know $\left(G 2^{\prime}\right) .^{7}$ Van Inwagen writes that he sees 'no way to construct an argument, an argument that employs reasoning that even superficially resembles my reasoning anent the teapot hypothesis, for the conclusion that, prior to the consideration

7 By contrast, see Swinburne (2004), chapter 5, who thinks the prior probability that God exists is not low whereas Mackie (1981), pp. 98-99, thinks that it is 'pretty low'. 
of such evidence as there may be for or against the existence of God, we ought to ascribe an extremely low probability to the proposition that God exists' (Van Inwagen (2012), p. 25).

Very often in discussions of the probability of a given hypothesis, by 'the prior probability of hypothesis $H^{\prime}$ the discussants mean the probability of $H$ prior to the evidence under consideration. In the present context of the debate between Russell and van Inwagen, we are to take it that there is no evidence for or against theism, and that means that there is no evidence under consideration. Accordingly, by 'the prior probability of theism' van Inwagen presumably means the probability of theism prior to any evidence at all. We might call this the intrinsic probability of theism.

Van Inwagen's reply implicitly makes a concession. He explicitly claims that there is no argument that shows that theism has a low prior probability. But he implicitly concedes that he has no argument to show that theism has any other prior probability - a middling or high prior probability. Otherwise I take it that he would offer such an argument. In that case he would not merely have no reason to accept (G2') but he would have reason to reject it as false. In short, van Inwagen is agnostic with respect to the prior probability of theism. This has various consequences; here are two of them.

First, if the prior probability of theism is unknown, then presumably so too are the prior probabilities of $F$ and $G$ - Hume's hypotheses about an infant and an infirm god. But then if a teapot-style argument against theism fails for the reason van Inwagen gives, it would also fail against $F$ or $G$. An agnostic about the existence of God would, I take it, also be agnostic about $F$ or $G$, but many philosophers would think it unreasonable to believe either $F$ or $G$ and reasonable to reject them. The question facing van Inwagen is on what remaining grounds it would be rational to reject $F$ or $G$.

Richard Swinburne has claimed that examples such as $F$ and $G$ are less simple, and thereby each has a lower prior probability, than theism (Swinburne (2004), chapter 5). Swinburne's claim is debatable: if $F, G$ and theism are competing hypotheses which might be used to explain some phenomenon - such as the order of the universe - then (1) what $F$ and $G$ each posit is infinitely weaker in respect of intelligence, power and freedom than what theism posits, although (2) each hypothesis otherwise does the same explanatory work as the other. Given these two facts, there is reason to think that $F$ and $G$ are each simpler than theism (cf. Van Inwagen (2002), p. 29). But in any case the avenue Swinburne takes is not open to van Inwagen. Since van Inwagen claims not to know what the prior probability of theism is, he is not in a position to say that it is higher than the prior probability either of $F$ or of $G$.

The puzzle is not confined to theological examples. Consider also: 
H Monads exist.

I Noumena exist.

$J \quad$ The neutral entities posited by Russell's neutral monism exist.

There is no evidence that monads, noumena or the neutral entities exist. I take it that the arguments for the existence of such entities fail. Nevertheless, the prior probabilities of $H, I$ and $J$ are unknown. At any rate, I am as confident that the prior probabilities of $H, I$ or $J$ are unknown as I am that the prior probability of theism is unknown. Yet it is reasonable to deny that monads, noumena or neutral entities exist. The puzzle is why this should be so, given the above response to Russell's teapot argument.

Second, if the prior probability of theism is unknown, then even if we find evidence which confirms theism more than it confirms its negation (i.e., atheism), then we will not know whether theism is more probable than not. Let us see how. First of all, what does it take for a piece of evidence to confirm a hypothesis? This is a much debated matter. Still, at least for the purposes of illustration, let's consider the following principle $(\mathrm{E}):^{8}$

(E) When a given piece of evidence $e$ is more probable on $H$ than on $H^{\prime}$ then e confirms $H$ more than $H^{\prime}$.

Suppose that there is a great deal of evidence $e$ which is more probable on $\mathrm{H}$ than on $H^{\prime}$ and so that e greatly confirms $H$ more than $H^{\prime}$. Suppose too that there is little or no evidence $e^{\prime}$ such that $e^{\prime}$ is more probable on $H^{\prime}$ than on $H$. Even so, unless we know what the prior probabilities of $H$ and $H^{\prime}$ are, we are not in a position to say that H's posteriori probability $-H$ 's probability given evidence $e-$ is greater than the posterior probability of $H^{\prime}$. For instance, suppose that $H$ 's prior probability is extremely low relative to $H^{\prime}$. Then, even given $e$, the posterior probability of $H$ need not exceed that of $H^{\prime}$. The same conclusion can be drawn using other principles of confirmation besides $(E)$ : if we are ignorant of the prior probability of a hypothesis $H$, we will be ignorant of what the posterior probability of $H$ is, given evidence which confirms $H$, and so we will be ignorant of whether $H$ is more likely to be true than $H^{\prime}$. A corresponding point holds with respect to the disconfirmation of hypotheses.

The background point is a familiar one. When we talk of confirming a hypothesis $H$ we may mean that evidence $e$ has raised the probability of $H$ as compared with what it was, or would have been, apart from e; or we may mean that $e$ makes $H$ more likely than not to be true (Swinburne (2004), chapter 1). If we are ignorant

8 Schlesinger reports that $(E)$ is the basis of scientific method: Schlesinger (1977), p. 157. 
of the prior probability of $H$, we can be in a position to know that $e$ has raised the probability of $H$ as compared to what it was or would have been, but we are not in a position to know that $H$ is more likely than not. Accordingly, even if the phenomena of consciousness, religious experiences, free will or morality each provide more evidence for theism than for atheism (as claimed in Swinburne (2004), if the prior probability of theism is unknown, then it will be unknown whether, given the evidence, theism is more probable than atheism. In sum, van Inwagen's response to Russell's teapot argument has a cost: it inadvertently enjoins agnosticism. ${ }^{9}$

What kind of agnosticism is this? That partly depends on the nature of our ignorance of the prior probability of theism. How might this presumed ignorance be alleviated? Would it be by empirical evidence? No, as we have seen, knowledge that there is empirical evidence for the existence of God would be posterior to, and so would not provide, knowledge of the prior probability that God exists. Would it then be by philosophical argument? The difficulty here is seeing how such argument would proceed. In the case of teapot, van Inwagen was able to argue that it had a low prior probability because its probability was equal to the (low) probability of the aggregate of the origin stories. No such parallel can be made in the case of the existence of God, an uncreated creator, since any origin story would have zero probability. But the less confident we are that we can have knowledge of the prior probability of theism, the higher our degree of belief should be that we cannot tell whether theism is more probable than atheism. But that is to say that our epistemic condition is that of Kantian agnosticism.

\section{Scriven's echo of Russell}

Michael Scriven has argued that, under certain conditions, the absence of evidence for an entity is evidence that there is no such entity:

But if we take arguments for the existence of something to include all the evidence which supports the existence claim to any significant degree, i.e., makes it at all probable, then the absence of such evidence means there is no likelihood of the existence of the entity. And this, of course, is a complete justification for the claim that the entity does not exist, provided that the entity is not one which might leave no traces ... and provided that we have

9 It does leave open the option that belief in God is properly basic: reasonable but not based on evidence (see Plantinga (1983), p. 77 and Wolterstorff (1983), pp. $176 \mathrm{ff})$, but there are independent objections to this option (e.g. Oppy (1994), pp. 157-159). 
comprehensively examined the area where such evidence would appear if there were any. (Scriven (1966), pp. 102-103)

Scriven's argumentative strategy - if an entity $x$ existed, there will be evidence $e$; there is no evidence $e$; so $x$ does not exist - is an instance of modus tollens. This reasoning is valid but does Scriven furnish true premises when he applies his strategy to the case of God? Scriven claims that his 'last proviso [in the above passage] is really superfluous since it is built into the phrase 'the absence of evidence" (Scriven (1966), p. 103, footnote 7). But the proviso is far from superfluous: the agnostic need not agree that if God existed, there would be evidence that he existed. That aside, even if the agnostic agreed that there would be evidence that God existed, the agnostic need not agree that we would know what that evidence would be. Scriven is concerned solely with an entity 'that might leave traces'. Now, what traces an entity leaves partly depends upon what activities it engages in, and, in the case of a sentient entity, what activities it engages in partly depends upon what it chooses to do. But, just as the agnostic suspends judgement about whether God exists, she also suspends judgement about what God would choose to do if he existed. Given the omniscience and omnipotence that God would have, and given the finitude of human beings, the agnostic does not presume to say what God would do, even given that God is omnibenevolent. The range of possible actions open to God that is consistent with his presumed nature is too large for the agnostic to judge what God would do. This is a special case of the more general but familiar point that a hypothesis makes predictions (and hence can be confirmed or disconfirmed) only in conjunction with various auxiliary hypotheses (Putnam (1979)). In a situation in which we are ignorant of which auxiliary hypotheses obtain, we would be ignorant of what predictions the hypothesis makes. Furthermore, it would be unreasonable to expect us to have knowledge of God's purposes without a detailed revelation from God of what those purposes are (Rowe (1988), p.127). Yet the agnostic is precisely someone who suspends judgement as to whether God has made such a revelation or what the content of that revelation is if God has in fact made one.

\section{Ockham's razor}

The agnostic says she lacks sufficient evidence to believe that there is a God or to believe that there is no God. Now, it might that thought that Ockham's razor comes into play in such an epistemic situation. But what should we take Ockham's razor to say? One formulation, an 'agnostic' formulation, says: if there is no evidence ei- 
ther supporting or disconfirming a hypothesis $H$, then we should neither believe $H$ nor believe not- $H$. One might wonder what evidence there could be for, or against, the principle expressed by that formulation (Plantinga (1983), p. 60 and Van Inwagen (2009)), but, setting that aside, the agnostic complies with the principle so formulated.

A contrasting formulation, an 'atheistic' formulation, says: if there is no evidence supporting an existential hypothesis $H$, then we should believe that $H$ is false. An existential hypothesis is one which posits the existence of some entity or some kind of entity. The negation of an existential hypothesis is not an existential hypothesis but a negative existential hypothesis. Consequently, if there is no evidence for $H$, the above principle implies that we should believe that $H$ is false. But, although there is no evidence for not- $H$, the fact that not- $H$ is a negative existential hypothesis removes it from the scope of the above principle.

The atheistic formulation of the Razor has been endorsed by Elliott Sober: "The principle of parsimony counsels that we should hypothesise that an entity does not exist, if its postulation is to no explanatory point” (Sober (1981), p. 145). Suppose that $H$ posits the existence of some entity which not some rival hypothesis $H^{\prime}$ does not, but that the converse does not hold. $H^{\prime}$ is then (ontologically) simpler than $H$. Suppose also that $H$ does not explain anything which $H^{\prime}$ fails to explain. Other things being equal, a simpler hypothesis explains matters better than a more complex one. So, for any evidence which either of these hypotheses explain, $H^{\prime}$ explains it better than $H$. Furthermore, for any pair of hypotheses, evidence confirms the hypothesis which would better explain the evidence. It follows that no evidence confirms $H$. Consequently, Sober's formulation entails that we should hypothesise that an entity or a kind of entity does not exist if there is no evidence for it. Sober claims that scientific practice follows the 'atheistic' formulation rather than the 'agnostic' one: physics eliminated the aether and evolutionary theory eliminated group selection. In each case the entity was explanatorily superfluous and so was not supported by evidence (Sober (1981), pp.145-146). What should the agnostic make of this?

First of all, here is a route which it is tempting to take but which unfortunately takes us full circle. Consider hypothesis $K$ :

\section{$K \quad$ The aether exists.}

Since physical bodies such as the Earth would move through the aether, the movement of these bodies should generate interference patterns. The MichelsonMorley experiment failed to detect such patterns and that would seem to count as evidence against $K$. But that is not the end of the story. Defenders of $K$, such as Fitzgerald and Lorentz, modified it by claiming that physical bodies contract 
along the line of motion according to a certain constant (the Lorentz factor), thereby accommodating these results. Now, it might rightly be said that Fitzgerald and Lorentz's contraction hypothesis was an ad hoc modification. But then what is wrong with a hypothesis being ad hoc? Perhaps the answer is that the more ad hoc a hypothesis is, the less simple it is, and that, other things being equal, we should accept the simpler of two rival hypotheses. Fair enough, but what attitude should we take to the less simple of the two hypotheses? Specifically, should we reject it as false or should we suspend judgement about it? We are back to the issue with which we started.

Here is another way to proceed. Despite the line of thought we examined above, it does not seem to be scientific practice to claim that an entity or a kind of entity does not exist if there is no evidence for it. Prior to July 2012 there was no evidence that the Higgs boson existed, but it was not scientific practice until that time to claim that the Higgs boson did not exist. Instead, scientists suspended judgement. Where does the difference with the case of the aether lie? The aether was characterised by a certain explanatory role: being the medium through which light is propagated. The Higgs boson is also characterised by an explanatory role: it is to explain why the weak force has a shorter range than the electromagnetic force and why the symmetries involving certain fundamental particles requires that those particles lack mass despite the fact that they have mass. The theory of special relativity does not require that anything occupies the first of these explanatory roles, but current physics finds it (at least) promising to take something to occupy the second of these roles. The resulting epistemic situation is as follows. Given our current scientific theories, there is no recorded data and we can expect there to be no data which the aether hypothesis is needed to explain. By contrast, given our current scientific theories, there are recorded data which the Higgs boson hypothesis might explain and for which we have no superior explanation. I suggest that this is why science denied the existence of the aether but did not deny the existence of the Higgs boson (prior to evidence of its existence coming in). As a first approximation, the principles at work here are:

(P1) If, given our background knowledge, there are no recorded data which a hypothesis $H$ is needed to explain and we should expect no data which $H$ is needed to explain, we should reject $H$ as false.

(P2) If, given our background knowledge, there is data which a hypothesis $H$ is needed to explain, or it is not the case that we should expect no data which $H$ is needed to explain, we should not reject $H$ as false.

To see how (P1) and (P2) apply, consider some earlier examples again: the hypotheses that Santa Claus, the Flying Spaghetti Monster, or the Great Pumpkin exist. Given our background knowledge of the world, there are no recorded data 
which these hypotheses are needed to explain, and we should expect no data which these hypotheses are needed to explain. By $(P 1)$, we should reject these hypotheses as false. By contrast, consider case $L$ :

$L \quad$ Intelligent extra-terrestrial beings within a thousand light-years of the earth exist.

Let us grant that there is no evidence for the truth of $L$. Nevertheless, that fact does not provide reason to believe that $L$ is false (Van Inwagen (2005), p. 133). The above principles apply to this example in the following way. Our background knowledge of what is to be found within a thousand light-years of the earth is very limited. We might, for instance, find monoliths of the sort portrayed in 2001: A Space Odyssey and they would be good evidence of extra-terrestrial activity. Given our limited knowledge of how the universe is furnished, it is not the case that we should expect no data which the extra-terrestrial hypothesis is needed to explain. By (P2), we should not reject $L$ as false.

Where does theism stand? Should the agnostic re-evaluate her position, given an acceptance of $(P 1)$ and $(P 2)$ ? In section 2 we distinguished three kinds of agnostic depending on whether the agnostic thinks that there was (a) very little evidence either way, or (b) no evidence either way, or (c) there could not be evidence either way.

An agnostic of kind (a) would think that, although, there is recorded data which theism is needed to explain, there is only very little such data. By $(P 2)$, she should not reject theism as false. She remains an agnostic. Agnostic of kinds (b) or (c) would think that there are no recorded data which theism is needed to explain - for otherwise the existence of such data would provide evidence that there is a God. The question then facing them is whether they think that we should expect no data which theism is needed to explain. An agnostic of kind (c), a Kantian agnostic, would claim that, since there cannot be such data, we should expect no such data. According to $(P 1)$, she should reject theism. She should become an atheist. The position of an agnostic of kind (b) involves an ambiguity: does she think that there are in a tensed sense - i.e., that there are up until now - no data? Or does she think that there are in a tenseless sense - i.e. that there were, are and will be - no data? If she takes the second way of disambiguating, then she expects that there will be no data which theism is needed to explain. By $(P 1)$, she should reject theism. She should become an atheist. If she takes the first way of disambiguating, she is faced with a choice point: from the fact that there currently are no data that need to be explained by theism, should we induce that there will be no such data? If she thinks we should induce this, then, by $(P 1)$, she too should 
reject theism. If she thinks we should not induce this, then, by $(P 2)$, she should not reject theism. She should remain agnostic. ${ }^{10}$

\section{Bibliography}

Dore, C. (1982), “Agnosticism”, in Religious Studies: 18, 503-507.

Draper, P. R. (2001), "Seeking but Not Believing: Confessions of a Practicing Agnostic", in Divine Hiddenness: New Essays, edited by D. Howard-Snyder and P. K. Mose, Cambridge: Cambridge University Press, 197-214.

Feldman, R. (2007), "Reasonable Religious Disagreements”, in Philosophers Without Gods, edited by L. Antony, Oxford: Oxford University Press, 194-214.

Hume, D. (1779), Dialogues concerning Natural Religion and Other Writings, edited by D. Coleman, Cambridge: Cambridge University Press, 2007.

Kant, I. (1781), Critique of Pure Reason, translated by P. Guyer and A. W. Wood, Cambridge: Cambridge University Press, 1998.

Le Poidevin, R. (2010), Agnosticism: A Very Short Introduction, Oxford: Oxford University Press. Mackie, J. L. (1981), The Miracle of Theism, Oxford: Oxford University Press.

Oppy, G. (1994), “Weak Agnosticism Defended”, in International Journal for the Philosophy of Religion: 36, 147-167.

Plantinga, A. (1983), "Reason and Belief in God", in Faith and Rationality, edited by A. Plantinga and N. Wolterstorff, Notre Dame: University of Notre Dame Press, 16-93.

Putnam, H. (1979), “The 'Corroboration' of Theories”, in his Mathematics, Matter and Method: Philosophical Papers, vol. I, Cambridge: Cambridge University Press, 250-269.

Rosen, G. (2001), "Nominalism, Naturalism, Epistemic Relativism”, in Philosophical Perspectives: $15,69-91$.

Rowe, W. L. (1988), "God and Theodicy”, in Philosophical Topics: 16, 119-132.

Russell, B. (1952), “Is There A God?”, in The Collected Papers of Bertrand Russell, vol. II: Last Philosophical Testament, London: Routledge, 543-548.

Schlesinger, G. (1977), Religion and Scientific Method, Dordrecht: D. Reidel Publishing.

Scriven, M. (1966), Primary Philosophy, New York: McGraw-Hill Book Company.

Shalkowski, S. A. (1989), “Atheological Apologetics”, in American Philosophical Quarterly: 26, 1-17.

Sober, E. (1981), “The Principle of Parsimony”, in British Journal for the Philosophy of Science: 32, 145-156.

Swinburne, R. (2004), The Existence of God, Oxford: Oxford University Press, 2nd edition.

Van Inwagen, P. (2002), “What is the Problem of the Hiddenness of God?”, in Divine Hiddenness: New Essays, edited by D. Howard-Snyder and P. K. Moser, Cambridge: Cambridge University Press, 24-32.

10 I am very grateful to Eve Garrard and Scott Shalkowski for comments on an earlier draft of this paper. I am also grateful to Robin Le Poidevin for discussion of the topic of agnosticism. 
Van Inwagen, P. (2005), “Is God An Unnecessary Hypothesis?”, in God and the Ethics of Belief: New Essays in Philosophy of Religion, edited by A. Dole and A. Chignell, Cambridge: Cambridge University Press, 139-151.

Van Inwagen, P. (2009), “Listening to Clifford's Ghost, in Royal Institute of Philosophy, Supplement: $65,15-35$.

Van Inwagen, P. (2012), “Russell's China Teapot?”, in The Right to Believe: Perspectives in Religious Epistemology, edited by A. D. Lukasiewicz and R. Pouivet, Heusenstamm: Ontos Verlag, 11-26.

Wolterstorff, N. (1983), “Can Belief in God be Rational If It Has No Foundations?', in Faith and Rationality, edited by A. Plantinga and N. Wolterstorff, Notre Dame: University of Notre Dame Press, 135-186. 
